\title{
Analysis of Contact Stresses in Altered Tooth-Sum Spur Gearing
}

\section{Sachidananda $\mathrm{HK}^{1 *}$, Joseph Gonsalvis ${ }^{2}$ and Prakash HR}

${ }^{1}$ Department of Engineering, Manipal University, Dubai Campus, UAE

${ }^{2}$ St Joseph Engineering College, Mangalore, India

${ }^{3}$ Department of Engineering, B.M.S. Institute of Technology, Bangalore, India

\begin{abstract}
Contact stress between the gear teeth in mesh determines the ability of the gear to transmit the power safely. In improving the contact strength of gear teeth, profile shift is found to be the best option beyond the use of high strength materials and surface treatment techniques. This paper discusses an alternate yet simple method of improving contact strength by the way of altering the tooth-sum. Altering the tooth-sum working between a specified center distances for a given module changes the operating pressure angle and hence necessitates profile shift. Using this profile shift gears can be designed to advantage. Few cases are considered for the purpose of discussion for clear understanding of the presentation. Large volume of monographs are developed which the practicing engineers can use.
\end{abstract}

Keywords: Profile shift; Contact ratio; Operating pressure angle; Contact stress; Radius of Curvature

\section{Introduction}

Gears are used for transmission of angular motion and torque from one shaft to another. They are required to deliver different angular velocities (Speed) and torque to meet the demands of many engineering applications. Gears are generated employing either cycloidal or involutes profile for the tooth. Among these, involutes profile is more commonly used tooth-profile for the gears because of simplicity in tooling and manufacture, they are less sensitive to small changes in center distance and tooth profile can be shifted along any part of the involute conveniently. The process of shifting the profile along the involute curve is also known as profile correction or profile modification. Method of providing profile shift is shown in Figure 1. In Figure 1(a) it is seen clearly that the pitch line A-A of the rack cutter is tangential to the pitch circle of the gear being generated. But in Figure 1(b) it is seen that the pitch line of the rack cutter is shifted away from the pitch circle and is denoted as A'-A'. This condition shows a positive profile shift. The amount of shift is expressed as a coefficient ' $x$ ' of module ' $m$ '. Hob offset has shown to be an effective way to balance the dynamic tooth stress of the pinion and the gear to increase load capacity [1]. Profile correction is used when small numbers of teeth have to be generated in order to overcome interference or undercutting [2]. Also, in gearing, the tooth action from the beginning of tooth contact till the pitch point is called approach action and from the pitch point till the point of break of tooth contact is called as recess

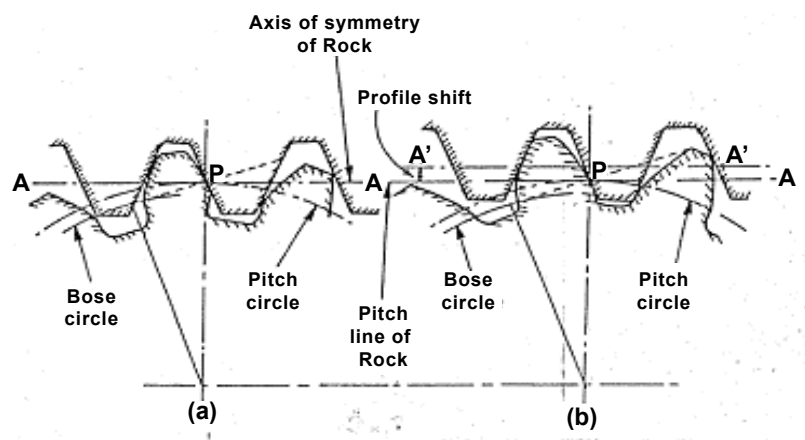

Figure 1a and 1b: Method of Providing tooth profile shift. action. By using the technique of profile shifting the gearing can be made to work either to have only approach or recess action or both in varying proportions [3]. Thus possibilities of profile shifting opens up many avenues to the problem of gear design. Costopoulus and Spitas [4] have introduced one sided involute asymmetric spur gear teeth to increase load carrying capacity and combine the meshing properties. Tesfahunegn et al. [5] investigated the influence of the shape of profile modifications on transmission error, root stress and contact pressure through nonlinear finite element approach. To improve the gear tooth strength many works have been done but all mostly employed positive profile shifting [6-7].

Alternatively, when profiles of the mating gears are shifted in

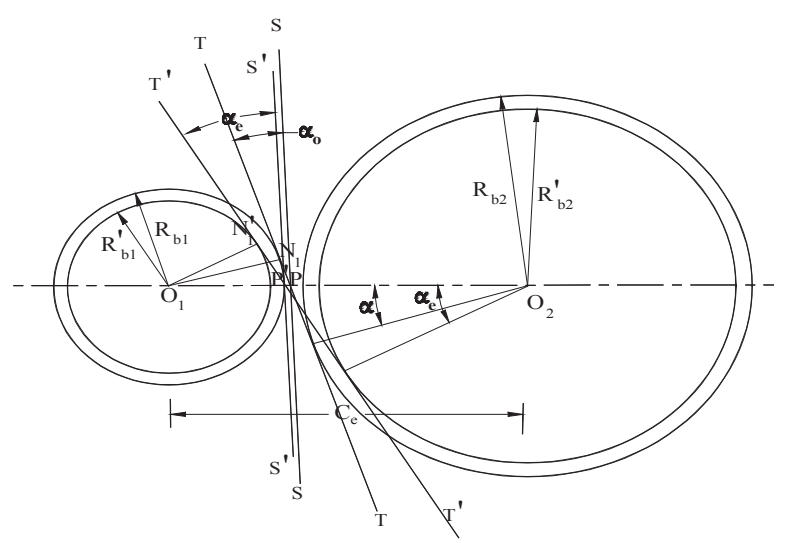

Figure 2: Operating Pressure Angle.

*Corresponding author: Sachidananda HK, Senior Lecturer, Department of Engineering, Manipal University, Dubai Campus, UAE, Tel: +971559328276; E-mail: sachidananda6@gmail.com

Received January 05, 2012; Accepted March 29, 2012; Published March 31 , 2012

Citation: Sachidananda HK, Gonsalvis J, Prakash HR (2012) Analysis of Contact Stresses in Altered Tooth-Sum Spur Gearing. J Applied Mechanic Engg 1:103. doi:10.4172/2168-9873.1000103

Copyright: (c) 2012 Sachidananda HK, et al. This is an open-access article distributed under the terms of the Creative Commons Attribution License, which permits unrestricted use, distribution, and reproduction in any medium, provided the original author and source are credited. 
opposite directions in equal proportions the standard center distance remains unaltered but unequal amount of profile shift results in change of center distance [8]. This property of involute tooth gearing can be used beneficially to make different tooth-sums to work between a specified center distances or for a given center distance and module the standard tooth-sum can be altered.

\section{Varying the number of teeth}

As said above, by employing profile-shifted gears of a given module

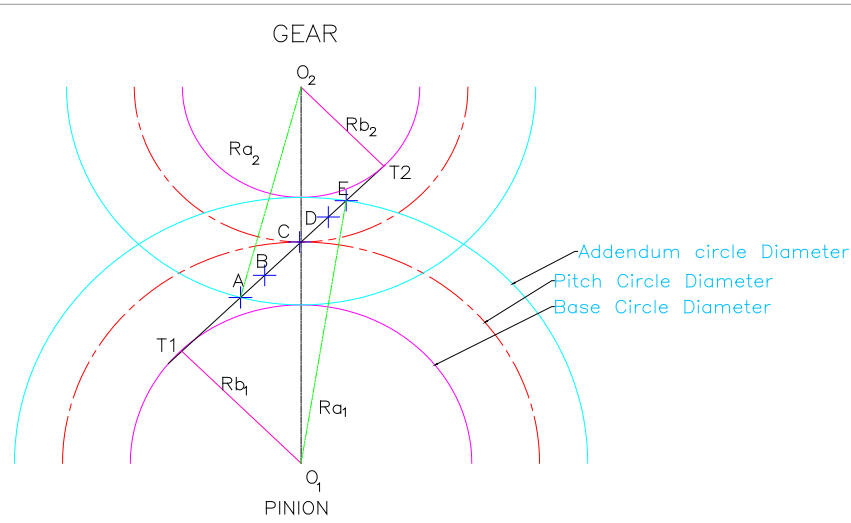

Figure 3a: Shows the path of contact for a pair of teeth in mesh from the beginning to the end described by the points $A, B, C, D$ and $E$.

A-Beginning of Contact; B1-End of Two pair mesh; B2-Beginning of Single pair in Contact; C-Pitch Point; D2-End of Single pair mesh; D1-Beginning of two pair mesh; E- End of Contact

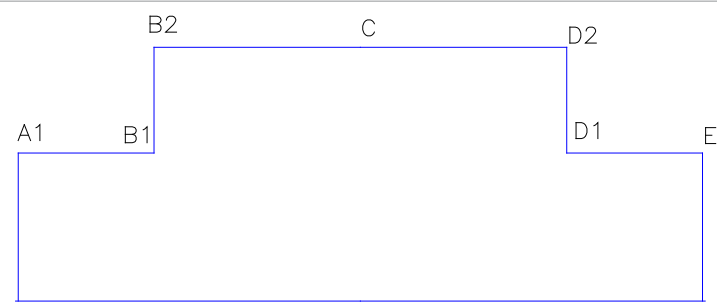

Figure 3b: Illustrates the load distribution between a pair of mating teeth along the path of contact A1 to B1 the load shared is half the full load, From B2 to D2 full load and from D1 to $E$ the load shared is half the full load when the contact ratio is between 1.2 and 2 .

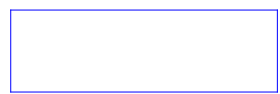

Figure 3c: It shows the load shared by a pair of mating teeth along the path of contact when contact ratio is equal to 2 . we can accommodate different tooth-sums between a specified center distances. Thus, when the number of teeth of a gear pair is altered the base circles of gears in mesh will also change and as the center distance is specified for the standard tooth-sum and module, the common tangent to altered base circles defines an operating pressure angle, $\alpha_{\mathrm{s}}$ which will be larger or smaller than the standard pressure angle. This situation is shown in Figure 2. It is reported in reference [9] that tooth-sums of gear pairs ranging from 40 teeth to 240 teeth can be altered by $\pm 4 \%$ and the corresponding amount of profile shift required to accommodate the altered tooth-sum and the operating pressure angle are being specified. The resulting profile shift can be distributed between the gears suitably. The table 1 gives details of for a tooth-sum of 100 and module $2 \mathrm{~mm}$, the center distance is $100 \mathrm{~mm}$ and on this center distance it is possible to accommodate tooth-sums ranging from a maximum of 104 teeth to a minimum of 96 teeth. For each tooth altered over the standard toothsum the gears will receive profile shift accordingly.

\section{Contact stress analysis}

Contact stress is a surface stress, which depends upon the load acting normal to the region of gear teeth contact and also the radii of curvature of the gear tooth-profiles. Contact stresses are calculated using Hertz Equation [1]. Contact stress determines the surface durability of gears, more commonly gears fail because of pitting and galling which are due to surface fatigue. Pitting and galling are largely responsible for tooth surface wear. Either using surface treatments or modifying the tooth geometry, such modes of failure can be reduced. Further, the load shared by the teeth along the path of contact varies from point to point which is illustrated in Figure 3(b) and 3(c). It is seen from the Table 1 that for an altered tooth-sum gearing the contact ratio varies from a

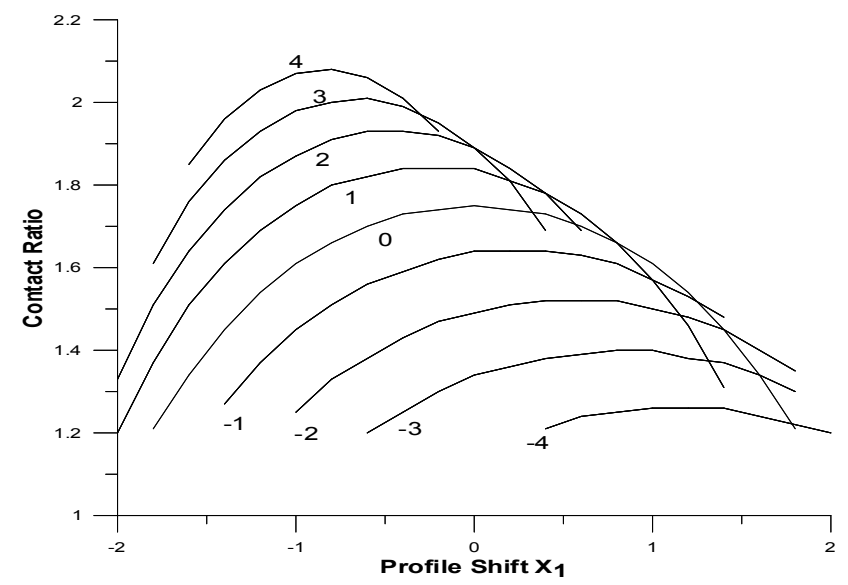

Figure 4: Variation of Contact Ratio with Profile Shift for $Z=100$ Teeth.

\begin{tabular}{|c|c|c|c|c|c|c|c|}
\hline $\begin{array}{l}\text { No. of teeth } \\
\text { Altered } Z_{i}\end{array}$ & $\begin{array}{l}\text { Altered tooth- } \\
\text { sum, } Z_{\mathrm{e}}\end{array}$ & No of teeth on pinion, $Z_{1}^{\prime}$ & $\begin{array}{l}\text { No of teeth on the } \\
\text { Gear } Z_{2}^{\prime}\end{array}$ & $\begin{array}{c}\text { Operating pressure angle } \\
\text { Degree, } \alpha_{s}\end{array}$ & Profile shift Xe & $\begin{array}{l}\text { Profile shift on } \\
\text { gears } X_{1}=X_{2}\end{array}$ & $\begin{array}{l}\text { Contact } \\
\text { ratio } \varepsilon\end{array}$ \\
\hline 0 & 100 & 50 & 50 & 20.00 & 0.00 & 0.00 & 1.75 \\
\hline 1 & 101 & 50 & 51 & 18.36 & -0.48 & -0.24 & 1.84 \\
\hline 2 & 102 & 51 & 51 & 16.56 & -0.92 & -0.46 & 1.93 \\
\hline 3 & 103 & 51 & 52 & 14.56 & -1.31 & -0.65 & 2.01 \\
\hline 4 & 104 & 52 & 52 & 12.24 & -1.65 & -0.82 & 2.08 \\
\hline-1 & 99 & 49 & 50 & 21.52 & 0.51 & 0.25 & 1.64 \\
\hline-2 & 98 & 49 & 49 & 22.94 & 1.07 & 0.53 & 1.52 \\
\hline-3 & 97 & 48 & 49 & 24.28 & 1.65 & 0.82 & 1.40 \\
\hline-4 & 96 & 48 & 48 & 25.56 & 2.27 & 1.13 & 1.26 \\
\hline
\end{tabular}

Table 1: Details of Altered Tooth-sum gearing for a Tooth-sum of 100 Teeth and Module $2 \mathrm{~mm}$. 
minimum of 1.26 to a maximum of 2.08 . At the same time the profile shift varies from +2.27 to -0.82 . The radii of curvature will be larger when the profile shift is positive and vice-versa. Hence judicious use of altering the tooth-sum and profile shift contact stress induced can be lowered. Thus this technique of altering the tooth-sum helps design gears for lower contact stresses and increase fatigue life of the gears. The contact stress is calculated using the Equation (1) given below.

$$
\mathrm{CS}=\operatorname{SQRT}\left(0.35 \mathrm{~F}\left(1 / \mathrm{R}_{1}+1 / \mathrm{R}_{2}\right) / \mathrm{L}\left(1 / \mathrm{E}_{1}+1 / \mathrm{E}_{2}\right)\right)
$$

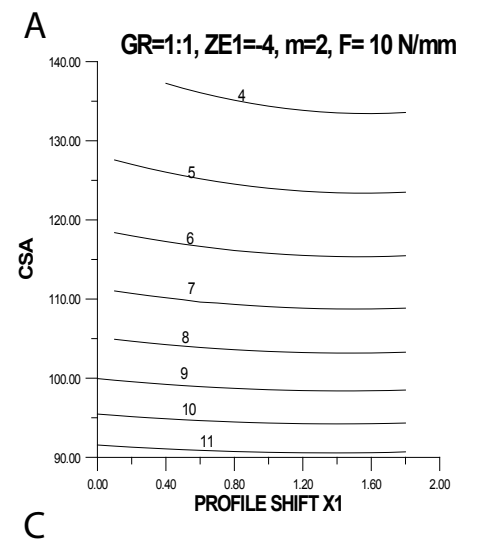

\section{$B \quad G R=1: 1, Z E 1=-4, m=2, F=10 \mathrm{~N} / \mathrm{mm}$}

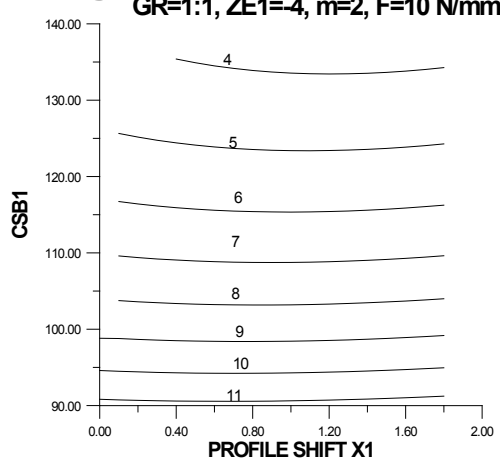

$\mathrm{D}$

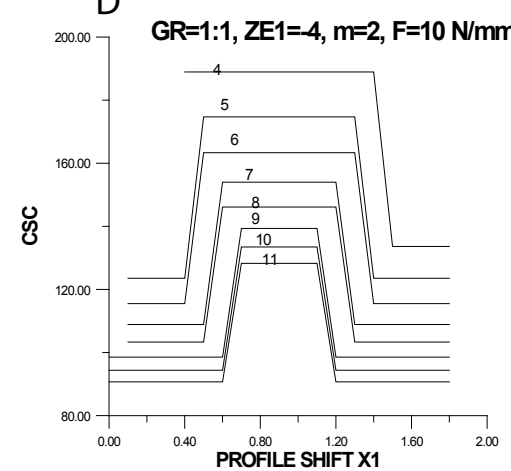

$\mathrm{E}$
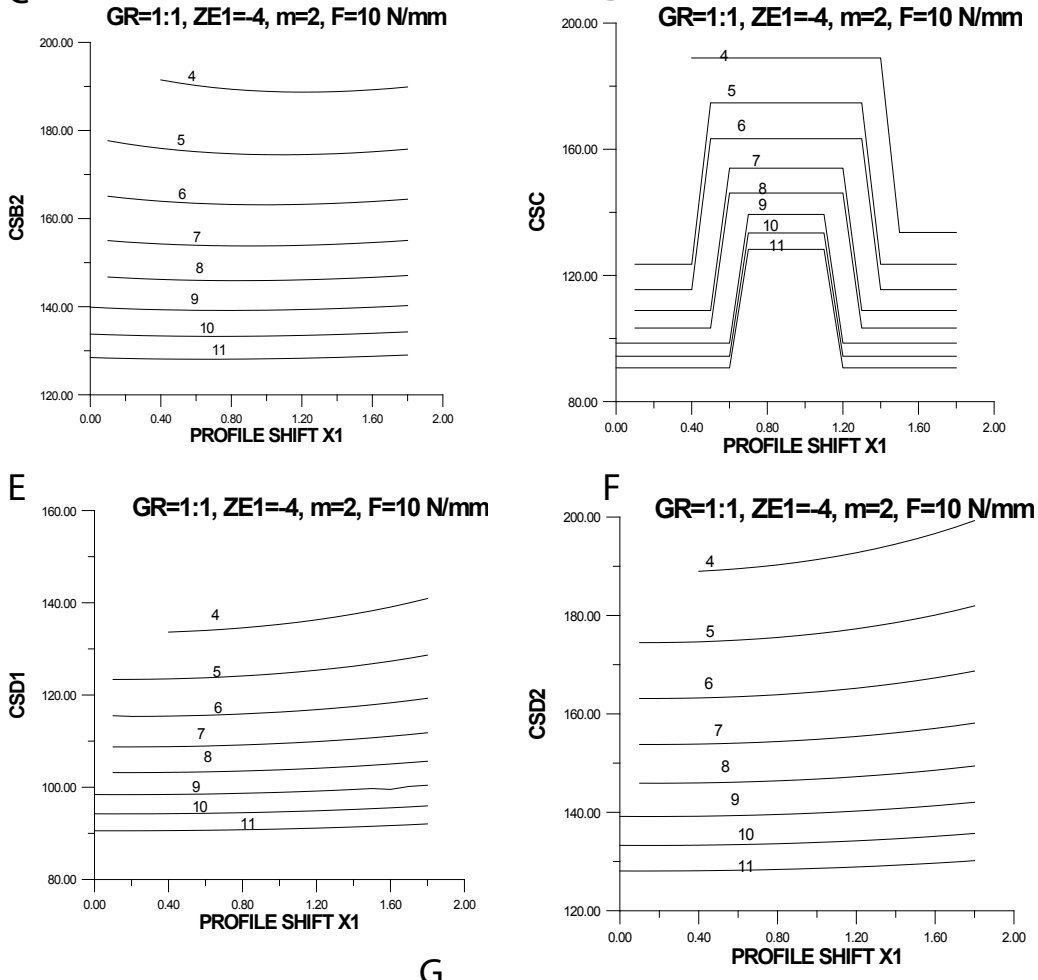

G

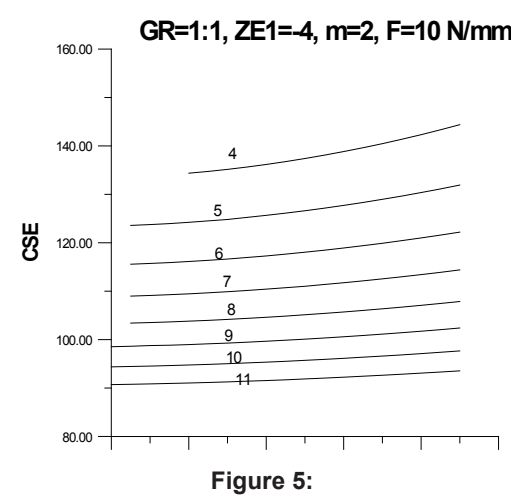




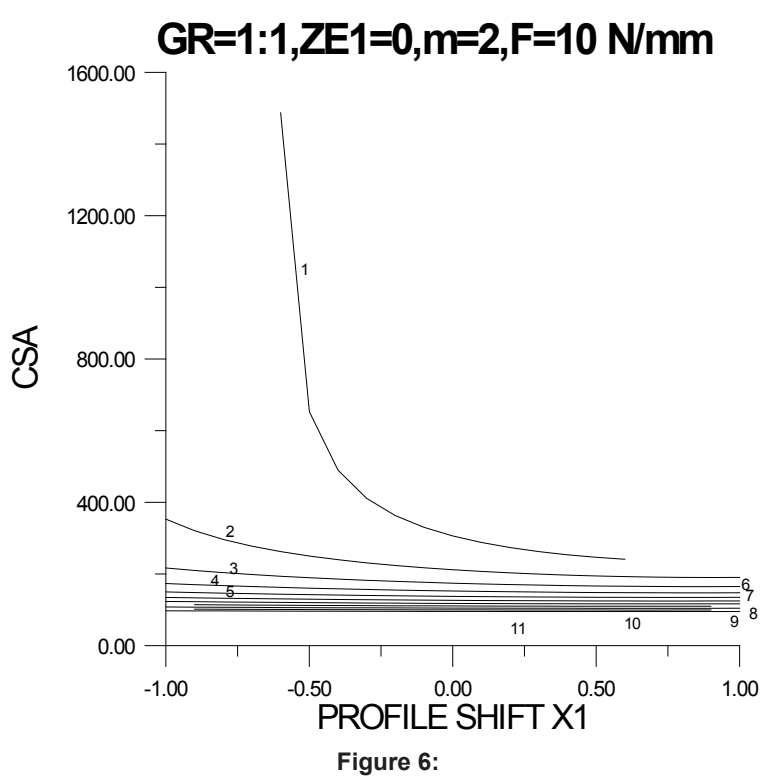

For the purpose of calculating the geometrical dimensions a module of $2 \mathrm{~mm}$ is considered. In order to facilitate plotting the values for visualization of stress distribution a normal tooth load of 10 Newton per millimeter length of the face width is taken. The pressure angle of generation is taken as $20^{\circ}$. The profile shift resulting due to alteration in the tooth sum is distributed between the gear pair in varying proportions taking care to see that tooth tipping, undercutting and minimum contact ratio for continuous gear operation have been considered. Material for the gears is taken as steel.

\section{Effects on contact ratio}

Contact ratio of a gear pair in mesh is the ratio of the length of the path of contact to the base pitch [10]. The contact ratio of a standard gear is affected only when the tooth profile is modified.

To study the effects of varying the number of teeth on the contact ratio the tooth sum of 100 may be considered. A gear ratio of $1: 1$ is used in all the cases and the tooth-sum is varied from +4 teeth to -4 teeth and the profile shift for each value of $Z_{i}$ is taken from the Table 1 . The corresponding profile shift is allowed on the pinion in varying proportions such that the algebraic sum of the profile shift remains equal to the value of profile shift given in the Table 1. Using a standard module of $2 \mathrm{~mm}$ the geometrical dimensions are determined and contact ratio is calculated. Figure 4 shows the variation of contact ratio for different values of $Z_{i}$ altered over the tooth-sum of 100 allowing the profile shift $\mathrm{X}_{1}$ on the pinion. The figure 4 illustrates the variation of contact ratio and it is observed that for positive values of teeth altered the contact ratio is higher and vice-versa. The values of contact ratio peak when the resulting profile shift due to alteration in tooth numbers is shared equally for gear ratio 1:1. This property can be used beneficially while designing gears which are uncommon to standard gearing.

\section{Effects on contact stress}

When a pair of gear teeth comes into mesh the contact between then theoretically is a line along the face width. The curvature of the tooth profile at every point of contact varies constantly for involute profile (Since the radius of curvature is proportional to the peripheral length of the base circle). Besides as contact progresses along the line of action, the tooth surfaces at the point of contact roll and slide.
Hence for a gear pair having contact ratio greater than 1 and less than 2 load is shared by two pairs for some time in the beginning and in the end of the path of contact. In figure 3 (a), 3(b) and 3(c) the different points along the path of contact are identified as A,B,C,D and $\mathrm{E}$ which indicate changeover of tooth-load from full load to half full load. It is evident from the equation (1) that the radius of curvature of the teeth is inversely proportional to the square of the contact stress. Hence the contact stress induced will be lower if the radii of curvature are larger. This property can be used as an advantage in the gears having involute tooth profile and for a positive shift the radius of curvature of the tooth profile increases and vice-versa. Altering the tooth-sum introduces profile shift using this profile shift judiciously the surface strength of the gears can be improved considerably without resorting to high strength materials.

In order to visualize the effects of varying the number of teeth on the contact stress, tooth sums ranging from 40 teeth to 240 teeth have been considered and the tooth sums are varied considering only -4 teeth. The profile shift due to the alteration in tooth-sum is allowed on the pinion in varying proportions such that the algebraic sum of the profile shift remains the same. The contact stress is calculated using equation (1) at various points as shown in figure 3. Contact stress at each point along the path of contact such as A, B, C, D and E is shown in figures $5(\mathrm{a})-5(\mathrm{~g})$. In these figures it is seen that contact stress nearly remains constant for different values of profile shift allowed on the pinion, a property which is unique. As a matter of comparison in figure 6 , contact stress variation is plotted at point 'A' for different tooth-sums but without any alteration in tooth numbers. Profile shift is allowed on the pinion in varying proportions taking care to see that the algebraic sum of profile shift is zero. Comparing the stress situation at contact point ' $\mathrm{A}$ ' in figure 5(a) for altered tooth-sum gearing (Number of teeth altered is -4). It is seen clearly that the stress values are far lower in altered tooth-sum gearing for all the range of tooth-sums considered. This feature clearly places altered tooth-sum gearing in respect to the problem of lowering the contact stress. The number shown from 1 to 11 on the plots indicates tooth-sums ranging from 40 teeth to 240 teeth in steps of 20 teeth.

\section{Conclusion}

Varying the numbers of teeth on a standard tooth-sum is of practical importance in gear transmission. To enable its applications the numbers of teeth varied on the tooth-sums are specified. Tooth-sums considered range from 40 teeth to 240 teeth, which are generally employed in most of the gear transmission applications. The above study shows very clearly that using altered tooth-sum gearing it is possible to tailor the drive either for high contact ratio or for lower contact stress.

A large volume of monographs has been developed considering tooth-sums ranging from 40 teeth to 240 teeth that are commonly employed in practice. The tooth-sums are altered by an extent of $\pm 4 \%$ of the tooth-sum. The variations of contact ratio as well as contact stress at different points of contact along the path of contact are plotted which practicing engineers and gear designers could use.

\section{References}

1. Tuan Nguyen, Hsiang H Lin (2011) Compact Design for Non-Standard Spur Gears. Journal of Mechanical, Aerospace and Industrial Engineering 2.

2. Maitra GM (2001) Minimum number of teeth to avoid interference. In: Hand book of gear design, Tata McGraw Hill, India.

3. Gustav Niemann (1980) Profile shift, Use and Calculation, Machine ElementsVol. II, Allied Publishers, New Delhi: 43-45, 112-119.

4. Costopoulos T, Spitas V (2009) Reduction of Gear fillet stresses by Using 
Citation: Sachidananda HK, Gonsalvis J, Prakash HR (2012) Analysis of Contact Stresses in Altered Tooth-Sum Spur Gearing. J Applied Mechanic Engg 1:103. doi:10.4172/2168-9873.1000103

Page 5 of 5

One sided Involute Asymmetric Teeth. Mechanism and Machine Theory 44: 1524-1534.

5. Tesfahunegn YA, Rosa F, Gorla C (2010) The Effects of the shape of Tooth Profile Modification on the Transmission Error Bending and Contact Stresses of Spur Gears. Journal of Mechanical Engineering Science 224: 1749-1758.

6. Mabie HH, Rogers CA, Reinholtz CF (1990) Design of Nonstandard Spur Gears Cut by a Hob, Conception d'engrerenages droits non standardises usines par une fraise. Mechanism and Machine Theory 25: 635-644.

7. Rogers CA, Mabie HH, Reinholtz CF (1990) Design of Spur Gears Generated
With Pinion Cutters, Conception d'engrenages droits realises par des outilspignons. Mechanism and Machine Theory 25: 623-634.

8. HE Merrit (1962) Effect of addendum sum in not equal to zero. Gears, Third Edition, Pitman, London: 124-125.

9. Joseph Gonsalvis, GVN Rayudu (1994) Effects of varying the numbers of teeth on a tooth-sum for a specified center distance-External Gears, Personal Communications.

10. Robert L Norton (2010) Machine Design an Integrated Approach. Fourth Edition, Prentice Hall: 694-695. 